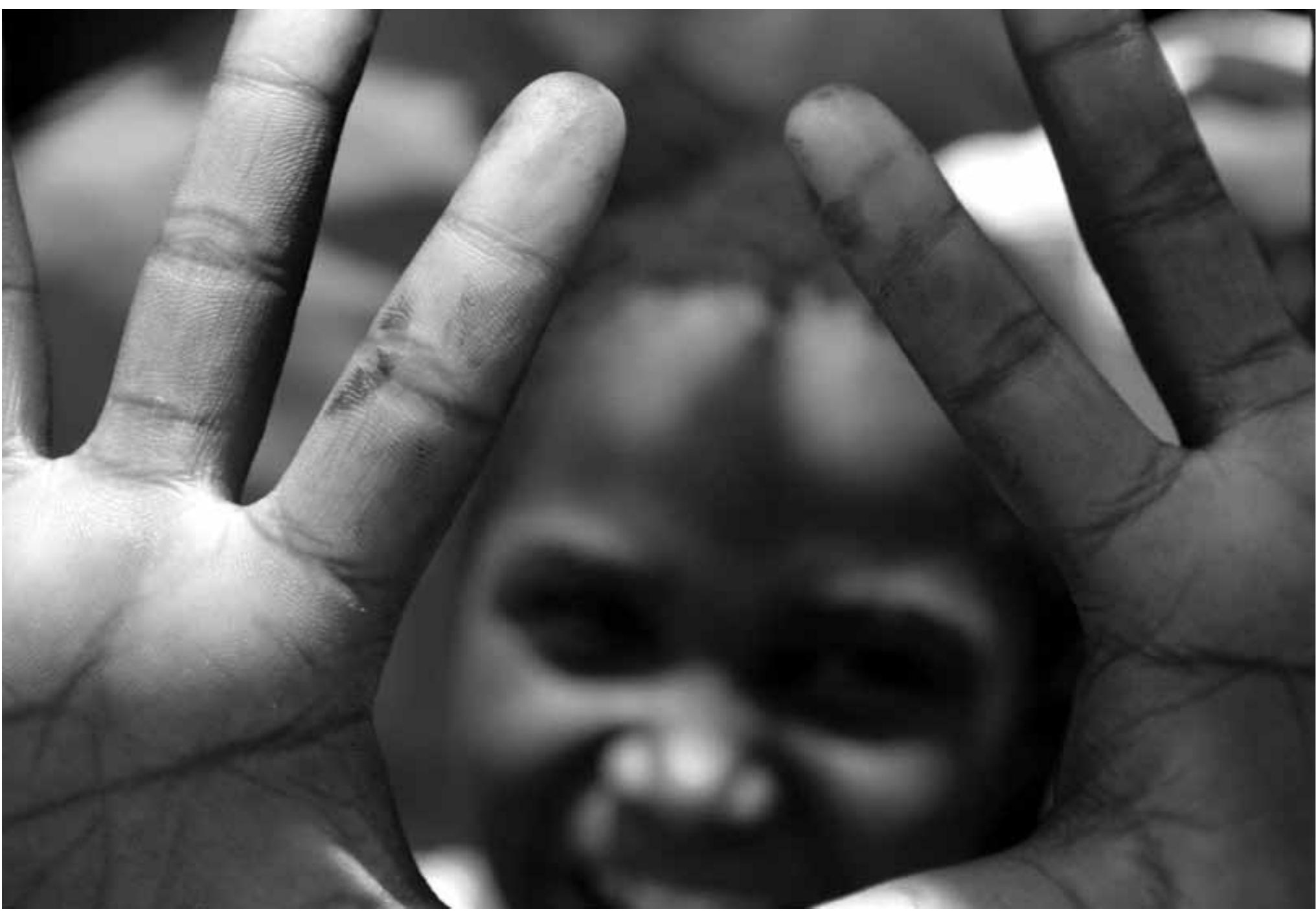

\title{
The Link between Sociall Inequality and Child Health Outcomes
}

Avram Denburg and Denis Daneman

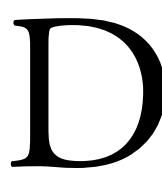

espite the scientific and technological advances of recent decades and their potential impact on healthcare delivery, major disparities in child health exist both between and within countries. Across the globe, over 25,000 children under five years of age die every day, the majority, but by no means all, in developing countries. Infant mortality is 10 times higher in the world's least-developed countries than in the industrialized world, and under-five mortality is 25 times higher (United Nations Children's Fund 2008). Vast discrepancies in child health also exist within high- and low-income countries.

In Canada, for example, major differences exist in two key indicators of child health, namely, rates of infant mortality and low birth weight. Overall, infant mortality in Canada has been 
reported as 5.4 per 1,000 live births, ranging from as low as zero and 2.2 in the Yukon and Prince Edward Island, respectively, to as high as 8.3 in Saskatchewan and 10 in Nunavut. Similarly, while the overall Canadian rate of low birth weight is six in 100 , it ranges from a low of 4.4 in the Northwest Territories to 6.9 and 7.3 in Alberta and Nunavut, respectively. Internationally, Canada ranks 24th among industrialized nations in rates of infant mortality and ninth in rates of low birth weight. The United States is buried even deeper, with a national infant mortality rate of 6.8 per 1,000 live births and a low-birthweight rate of 8.1 per 100 newborns (Raphael 2010a).

Inequalities in child health outcomes trace an impressively linear socio-economic gradient. Overall, child mortality levels correlate closely with income quintile, with those in the lowest income brackets most severely affected (Marmot 2005). Among wealthy nations, Canada and the United States rank 20th and $27 \mathrm{th}$, respectively, in the percentage of children living in relative poverty $(15 \%$ and $21 \%$, respectively). These rates are four to seven times higher than those in the countries with the lowest rates of child poverty: the Scandinavian countries, for instance, contend with child poverty rates of only $3-5 \%$. The incidence of low birth weight, an important determinant of health over the lifespan, is on the rise in high-income countries, its burden falling heavily on families in lower socio-economic strata where identified demographic and psychosocial risk factors concentrate (Ohlsson and Shah 2008). There is, likewise, mounting evidence of socio-economic gradients in education and behaviour, and concomitant proof of their dynamic interaction with health outcomes (Fiscella and Kitzman 2009; Keating and Hertzman 1999). There is also gathering evidence that socio-economic inequities contribute to wider variations in health and other outcomes. In their book The Spirit Level, Richard Wilkinson and Kate Pickett (2009) synthesize compelling evidence demonstrating that almost every modern social and environmental problem - be it illness, drugs, violence, increasing prison populations, obesity, mental illness or long working hours - is more prevalent in less equal societies. Equality in this context is gauged by the degree of discrepancy between high- and low-income earners in a particular society. Once again, Scandinavian countries boast the lowest income inequality, Canada falls in the middle of the pack and the United States plots at the very extreme.

Accruing data point to a causal relationship between early life experiences and subsequent health, education and behavioural outcomes, one mediated through impacts on brain architecture and function during critical periods of neural development. There is increasingly robust biological evidence to account for the manifest links between socio-economic inequalities and gradients in health, behaviour and cognitive development across the lifespan (Mustard 2007). These relationships take root in, and are conditioned by, patterns of experience during early childhood, and depend upon associated determinants of child health, including maternal health, fetal and neonatal nutrition and nurturing. There is, therefore, a case to be made for policies that attend to disparities in opportunity by mitigating differential risk in early childhood environments (Denburg and Daneman 2010).

This article seeks to map the social determinants of child health by exploring reciprocal currents between the science of experience-based brain development, the theory and epidemiology of societal gradients in health and the attendant impli-
Figure 1. Life expectancy at birth plotted against gross domestic product per capita, 139 countries

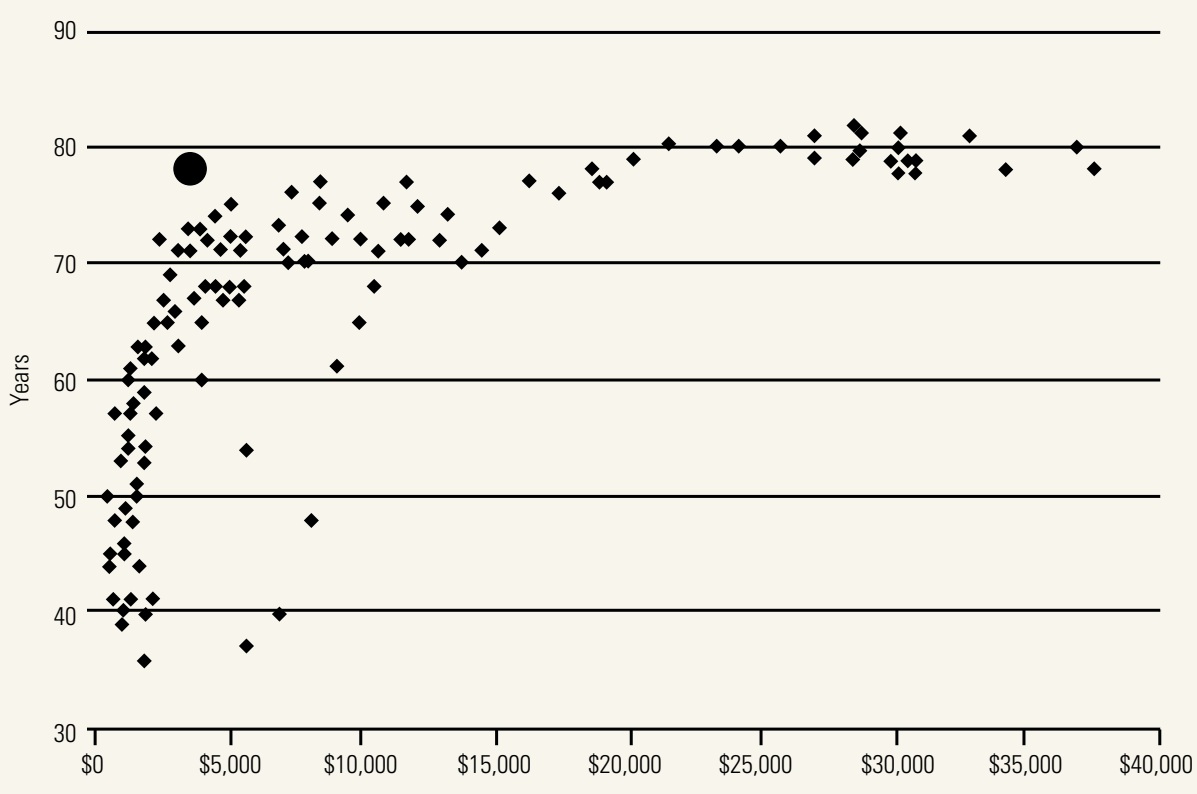

Source: Reproduced with permission from World Health Organization (2006) 
cations for social policy. To this end, we first provide a brief overview of the wide-ranging literature on the social determinants of health inequalities. The following section navigates the biology and ecology of early childhood development (ECD), testing consonance between models of neural development and evidence for social impacts thereon. We close with policy prescriptions intended to mitigate disparities in ECD and thereby attenuate social inequalities in child health.

\section{Almost every modern social and environmental problem - be it illness, drugs, violence, increasing prison populations, obesity, mental illness or long working hours - is more prevalent in less equal societies.}

\section{What Are the Social Determinants of Health? The Gradient}

Many studies have explored the relationship between social circumstance and health outcomes over the past half-century, seeking causal pathways between the two. The association between poverty and ill health is among the most robust and pervasive. A curvilinear relationship between income levels and life expectancy exists across countries, with the steepest portion of the curve at the lowest levels of income (Figure 1). The absolute income hypothesis interprets this relationship as the summative product of increasing deprivation on health: the greater the material want, the worse the health outcome. Those on society's lowest rungs are predictably sicker and die younger than those substantially and continuously above the poverty line. Many of the potential impacts of poverty upon health are intuitive, particularly where material deprivation is severe. Constrained access to potable drinking water, adequate nutrition, proper shelter and essential medicines conditions health outcomes for much of the world's population. This is rudimentary social arithmetic in many low-income countries, where resource scarcity is front and centre.

Less obvious are the effects of relative social or socio-economic inequality on individual and population health, and the causal mechanisms that relate them. In wealthy countries, the plight of the have-nots is more easily hidden or brushed aside.

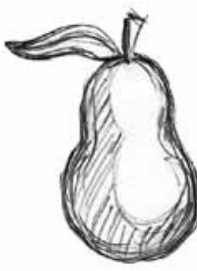

nutrition
Above a threshold, increasing income seems to have diminishing marginal effects on life expectancy. For example, life expectancy in Costa Rica correlates well with that of the United States, despite the significant gulf in gross domestic product (GDP) per capita between the two (United Nations Development Progamme 2003). And yet within each country, differences in life expectancy dovetail closely with socio-economic status. The "relative income hypothesis" contends that, above the threshold, it is the existence of inequality itself that engenders health disparities within societies (Wilkinson 1996). Convincing evidence attests to the close association between relative gradations in social standing and disparities in health. Income is a strong component of social position, but by no means the only one (Marmot 2005).

Evidence of a gradient in health across all social strata is well documented, even at income levels well above the national poverty line for a given country. Despite falling overall mortality rates following the introduction of the National Health Service in 1948, the mortality gradient across social classes in the United Kingdom grew steeper over the intervening decades. An inquiry into causes of this trend culminated in the landmark "Black Report," released in 1980, which concluded that, while medical care and public health interventions contributed to reductions in overall mortality, socio-economic inequality was a critical determinant of the gulf in life expectancy across social classes in Britain (Black 1980). More recently, the 1998 "Acheson Report" confirmed and updated many of its predecessor's findings and recommended the institution of fiscal, social and environmental policies to attenuate UK health inequalities (Acheson et al. 1998). Experience has shown that, while relatively easy to recommend, such policies are often difficult to implement and their goals even harder to achieve.

Social class has proven a fairly linear correlate of mortality in a number of studies, irrespective of absolute levels of income. The Whitehall Studies (Marmot 2004; Marmot et al. 1978), prospective cohort studies of UK civil servants, remain pivotal

\section{Income has its benefits measured by ...}

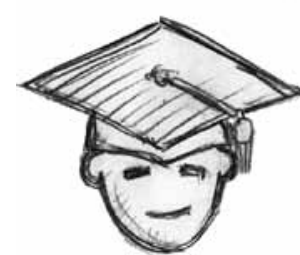

education

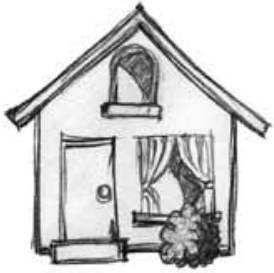

housing

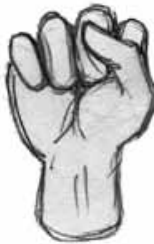

political position 
in this regard. The investigators examined a swath of allied occupations that nevertheless admitted of distinct internal social hierarchy. Long-term follow-up with this cohort has demonstrated a clear social gradient in all-cause mortality along class lines (Marmot 2004; Marmot et al. 1978). The class-dependent spread in life expectancy among a segment of the populace well above the national poverty line is taken as ecological proof of the link between relative social standing and life expectancy. Mackenbach et al. (2008) broadened the scope of this finding in a comparative study of 22 European nations. They found that socio-economic status served as a strong independent predictor of mortality rate, both within and across the highly varied groups studied. Their findings were independent of epidemiology, disease risk factors and health system characteristics. In other words, the existence of inequality per se seems to predict, and potentially fashion, disparities in health within and across societies. Debate continues over which theoretical model - the absolute or relative income hypothesis - best accounts for the observed socio-economic gradients in health. The normative implications of each, however, seem largely consonant: where inequality thrives, health does not.

\section{Experience has shown that, while relatively easy to recommend, policies to attenuate health inequalities are often difficult to implement and their goals even harder to achieve.}

\section{Which Way Does the River Flow?}

How then do we account for this link between socio-economics and health? A pitched debate has raged over the nature and direction of causation. Is it the social environment that determines our health? Or does our pre-existing state of health dictate our chances in society? Does poverty beget disease, or disease, poverty? Or is it something other than income that conditions the relationship between social standing and health? This debate is more than academic since commitment to one or other causal argument may dictate radically different policies.

There are those who read the evidence to suggest that income and its benefits - principally, enhanced nutrition but also better education, housing and political position - account for the bulk of the social gradient in health. McKeown theorized that rising prosperity and nutrition accounted for much of the decline in mortality from tuberculosis in 19th century England (McKeown 1976; McKeown and Brown 1955). Though criticized for giving short shrift to the effects of improved public health interventions during the same period (Szreter 2002), McKeown's work tells an important story about the role of wealth in shaping the health of populations. It proved an instrumental catalyst for further research into the effects of nutrition on aggregate health outcomes.

A number of historical studies have since demonstrated close and predictable associations between income, nutrition, height and life expectancy within and across defined population groups (Eckstein et al. 1985; Fogel 1994; Galloway 1986; Wrigley and Schofield 1981). Evidence suggests that peak adult height is inversely proportional to the risks of chronic disease and mortality, and that mean population height is determined largely by environmental factors, nutritional status chief among them (Marmot et al. 1984; Waaler 1984; Wohl 1983). Adult height reliably predicts life expectancy in many historical analyses of population mortality data: where mean population height has increased, so too has life expectancy, and vice versa. These trends seem to dovetail with measures of economic growth and income inequality across the countries studied (Fogel 1991; Frank and Mustard 1994). Moreover, height discrepancies along class lines are evident: greater income inequality corresponds to larger discrepancies in aggregate height across classes within a given society. Conversely, countries with high levels of income equality have largely erased class-based differentials in height (Bruntland et al. 1980). Income, as manifest in nutritional proxy, clearly plays a role in the observed health gradient across socio-economic strata. However, it is only part of the story. A singular focus on the association between income and health tends to foster policies focused on economic growth as the primary engine for aggregate improvements in health. Our interpretation is that this alone is inevitably insufficient to improve overall health in the society in question.

Others theorize "reverse causation." The "health selection" model presumes that good health leads to prosperity. This approach contends that we can mitigate poverty and social inequality by preventing or treating disease. This gives more weight to the effects of public health provisions and health systems strengthening on collective social welfare. Given the evidence on social causation of health outcomes, a pure health selection argument is not readily defensible. However, credible pathways from ill health to poverty and underdevelopment can be mapped. Evidence suggests an inverse correlation between infant mortality rates and economic growth, and a concomitant relationship between rising life expectancy and economic development. There is also evidence that demonstrates economic stagnation in the context of rising disease prevalence. For instance, high malaria burden has been shown to reduce growth by $1 \%$ per year or more in select sub-Saharan African countries (Sachs and Malaney 2002).

The channels of influence from health status to economic development are evident at multiple levels of social organization. Direct economic losses occur at the level of the individual, family or household, community and society. Individuals suffering from disease are subject to economic instability due to the cost of care associated with illness, loss of labour market 
income, loss to adult earning potential from childhood illness or loss of future earnings as a result of premature mortality. Moreover, there are reductions in mental health that are not reflected in most measures of economic well-being. The value of an extra year of healthy life is dependent on the summative effects of potential losses in market income, longevity and psychological well-being. Living with a chronic disorder has significant impacts on a number of measures, including productivity and quality of life. This reality is reflected in the concept of a quality-adjusted life year (QALY), a measure that assigns value to life based on health states, with healthy years ranked highest. The QALY is itself a controversial concept, not least because of its clumsy handling of mental disability. Even so, it implies that pure reductions in gross national product do not capture the full economic losses caused by ill health, and that more nuanced measures of human worth are needed to capture the value of life lost to disease (Commission on Macroeconomics and Health [CMH] 2001; Philipson and Soares 2001).

Economic losses to the family or household due to illness are often severe, most particularly where social protections are flimsy. Costs of treatment can throw households into economic chaos as many lack the type of insurance that is required to protect against catastrophic illness. This limits economic development in other areas as resources are exhausted on disease treatment (Gertler and Gruber 2002). A vicious cycle between childhood mortality and decreased parental investment in children also suggests the play of health selection within families in many developing countries. Strong evidence has linked increases in infant and under-five mortality to increased fertility rates (CMH 2001). Becker and Tomes (1976) have argued that higher fertility rates force "quantity-quality" tradeoffs in resource-constrained settings as there are fewer resources to invest in education and nutrition for each child. As alluded to above, Fogel (1994) has demonstrated links between body size, food supply and labour productivity, illuminating the importance of proper nutrition and health for economic productivity.

The link between health and education in such contexts is crucial. Childhood health is central to an effective and sustained capacity to learn. Biologically, cognitive and physical infirmities may limit educational attainment, which, in turn, constrains adult economic productivity. Where childhood disease is rampant, problems of absenteeism abound; early dropout from school limits one's ultimate earning potential in predictable ways (Bhargava and Yu 1997). Poor health may also affect a child's ability to concentrate when at school. Studies have linked nutritional deficiencies and enteric parasitism among children in the developing world with worse educational and developmental outcomes (Bhargava et al. 2001; Miguel and Kremer 2004; Pollitt 1997). Such problems are easily and cheaply remedied through public health intervention, and their correction produces impressive economic returns (CMH 2002). Poverty
- a lack of school fees, uniforms and proper nutrition - no doubt conditions the interplay between disease and education, but endemic disease often creates the conditions for sustained poverty from childhood onwards (Grantham-McGregor et al. 2007). As a result, the ability of children with chronic diseases to attend school and perform optimally is often dependent on a close collaboration between the health and education systems. Employing nurses to help children with type 1 diabetes perform blood glucose monitoring and insulin dose administration during school hours is just one example. Lastly, there is also economic fallout from the inter-generational spillover of disease. Parental infirmity results in a reduced ability to care and provide for children, as well as a reduced transfer of knowledge across generations (Bloom et al. 2001).

High disease burden induces not only individual and family losses but industry, community and societal losses as well. Population health instability risks decreased returns to business and infrastructure investment. Lower life expectancy results in decreased economic productivity and increased labour turnover - yet, ironically, a decreased labour pool. The need to train multiple people for the same job embeds technical inefficiencies in industry and discourages foreign investment (CMH 2001). Epidemic disease places strain on national budgets, inflating costs of care beyond the state's capacity to provide it. The need to allocate increasing funds to the health sector diminishes the capacity to invest in other sectors (CMH 2002). Ironically, the need for enhanced public funds often occurs in the context of drained governmental coffers: falling tax revenues from decreased capital accumulation at the individual level secondary to high disease burden. The human immunodeficiency virus/ acquired immunodeficiency syndrome pandemic in Africa is a quintessential example: it has abetted a massive economic slowdown of several percentage points per year due largely to the loss of a productive workforce (McDonald and Roberts 2006). Similar impacts may be seen in wealthy countries associated with massive increases in obesity and type 2 diabetes.

There are also data to suggest that basic public health interventions can improve population health without antecedent economic development. A 1985 Rockefeller Foundation report titled Good Health at Low Cost (Halstead et al. 1985) identified five regions with health indicators markedly above those expected given their per capita income levels: China, Costa Rica, Sri Lanka, Cuba and the Indian state of Kerala. In each case, reductions in infant and early childhood mortality rates accounted for a significant proportion of the gains in life expectancy. Comparative analyses of Kerala, Sri Lanka and Costa Rica show notable social parallels. Dominant themes include a high degree of female autonomy, open political culture, mutable class structure and a history of egalitarianism, political contest and populism.

The Keralan experience is instructive. Despite low per capita income and a fragile economic base, Kerala has lower infant, 
child and maternal mortality rates, lower rates of under-nutrition, lower birth rates, higher life expectancies and higher literacy rates than the rest of India and most low-income countries. Moreover, there is a largely equitable distribution of these outcomes between male and female citizens, urban and rural communities and various castes (Government of Kerala 2006). The reasons for these successes in the face of poor economic performance are diverse. As with the other "good health at low cost" countries, however, the prioritization of limited public funds for primary healthcare and education was integral. On the healthcare front, Kerala established a wide and far-reaching network of primary and community health centres; to date, it has one of the highest levels of per capita expenditure on healthcare in India (Government of Kerala 2006; Kutty 2000). Nutrition policies included free noon meals for schoolchildren; supplementary nutrition programs for preschool children and pregnant women; and subsidized essential foodstuffs at "fair price shops." An emphasis was also placed on water and sanitation. As of 2001, 64\% of the population received piped water, $84 \%$ of households had latrines (the highest level in India) and the vast majority of both urban and rural households had toilets (Government of Kerala 2006). The Kerala government also instituted free education for all children and built a wide network of libraries and reading rooms as adjuncts to formal education. This educational policy has been identified as a driver of social mobility, enhanced knowledge about health determinants and healthy behaviour and delayed child-bearing among young women (Jeffrey 1992). Other crucial elements of social policy included labour policy reform, improved social welfare provisions and political representation and advocacy at the grassroots level.

In recognition of this and similar evidence supporting reverse causation, the Commission for Macroeconomics and Health has stated: "a concerted attacked against [underweight, communicable diseases and maternal mortality] ... inherently constitutes a poverty-reduction effort in which benefits will accrue disproportionately to the poor. Investments in health therefore merit a special pride of place in strategies for poverty reduction" (2001: 22-23).

As is evident, the dichotomy between socio-economic and health selection paradigms is overly simplistic. In truth, the river flows both ways. Neither hypothesis is sufficient to explain health outcomes in either high- or low-income countries; the relationship between poverty and health outcomes is multifaceted. Income is an integral, but partial, determinant of population health outcomes. Policies aimed at raising aggregate levels of income - for instance, through investment in the private sector, market liberalization, stable conditions for trade and business and effective government stewardship - are essential but, pursued alone, inadequate. They neglect the a priori necessity of basic levels of health for economic development.
Moreover, they focus on long-term outcomes, through gradual market changes, at the expense of more immediate gains in health status possible through basic public health provisions. This permits significant inequalities in individual and community health outcomes - ones that key public health interventions could mitigate. In short, exclusive focus on either income or public health systems is simplistic and short-sighted.

A synergistic approach is required, one that recognizes the fundamental role of socio-economic conditions in determining health outcomes but also the need to achieve minimum levels of health for economic development to take root. As Wagstaff et al. (2004) have shown, the proximate determinants of child health - those that affect child health directly, such as perinatal care for mothers, preventive activities and care during illnesses - show broad improvement with improvements in underlying determinants of health - those that affect child health indirectly through their effect on proximate determinants. However, other distal determinants (political, social and economic contexts) have been shown to be essential as well, including maternal education, household income, the price of healthcare services, the features of healthcare provision and sanitation practices.

Sen's notion of poverty as "capability deprivation" encapsulates the nuance of these causal pathways (Sen 1999). His focus is on the ends that people need for development, rather than the means of achieving it, with a view to illuminating the freedoms necessary to achieve these ends. Sen contends that a person's capabilities - namely, "the substantive freedoms he or she enjoys to lead the kind of life he or she has reason to value" - are integral to human development (1999: 87). Poverty, in this model, means more than a simple lack of financial resources. The "capability approach" to poverty recognizes the importance of income deprivation, but as instrumental rather than intrinsic to human development. It enables a broader, more multi-faceted appraisal of the causes of poverty by focusing on the generation and deprivation of capabilities for development. Importantly, this conceptual model also recognizes the variable relationship between income deprivation and capability deprivation across individuals, families and societies. Income deprivation may matter more or less in different circumstances, depending upon the status of other determinants of capability. For instance, environmental and demographic factors - including age, gender, social roles and epidemiologic and environmental contexts - may radically condition the impact of income deprivation on one's health and capacity for development. This recognizes the potential for "coupling" of disadvantages: namely, the intertwined effects of income and other capabilities, such as handicap and productivity or childhood disease and adult earning potential, that purely income-based explanations of the health gradient lack. It also allows for a contextual appraisal of income deprivation, noting that developmental capabilities might be more limited for someone who suffers significant relative income 
deprivation, but has an absolute income level above that in many poorer countries, as her relative social functioning will be more severely constrained. Drawing on Sen's work, Ruger has cast health as a kind of higher-order capability, without which one could realize no other freedoms (Ruger 2006).

World Health Organization (WHO) analyses of global health risks support a synergistic appraisal of the relationship between poverty and health. The WHO 2002 report enumerates the "top 10 risks to health" globally, and argues that we may mitigate most through a mix of economic policies and public health solutions (WHO 2002). Many of these risks - such as underweight, unsafe water, poor sanitation and hygiene, iron deficiency and indoor smoke from solid fuels - could be alleviated through economic development. However, many are also amenable to improvement through basic public health interventions, be they health promotion practices related to hygiene, cooking and safe sex; improved public infrastructure for water and sanitation; micronutrient supplementation; or school food programs. While these interventions are not a panacea or a substitute for economic development, they are integral first steps to enabling development.

\section{If sensitive-period experience shapes developmental opportunities throughout the lifespan, it has the capacity to engender durable and heritable patterns of social deprivation and illness.}

The concept of social determinants of health, understood holistically, encompasses both views of causation and more. Material deprivation certainly breeds disease: childhood mortality, for instance, has proven particularly sensitive to the ravages of poverty (Marmot 2005). With this in mind, one of the pivotal Millennium Development Goals is to attenuate childhood mortality by alleviating material deprivation in low-income countries (United Nations Development Progamme 2000). The inverse is likewise true, as evinced by the Keralan experience. Robust and sustained attempts to achieve a core set of public health targets - including water and sanitation efforts, universal immunization coverage, nutritional campaigns, female literacy and empowerment around birth control - can make significant inroads into population disease burden in particular contexts. This may serve to both diminish the slope of the health gradient and provide a stable foothold for continued social gains by those on society's lowest rungs.

But this focus on one river, even when looking in both directions, is arguably myopic. A number of prominent thinkers, Marmot and Wilkinson among them, postulate that though income is an essential determinant of health, it is only one among many interrelated social determinants. The others include social position, employment, stress, early life experiences, social exclusion and social support systems (Wilkinson and Marmot 2003). Moreover, they see something crucial in the way in which societies, and communities within them, organize themselves. The idea of social capital has come to figure prominently in attempts to explain the dance between social standing and health (Wilkinson 1996). Other putative psychosocial pathways include effort-reward imbalance (Siegrist 1996; Siegrist et al. 2004) and stress secondary to a lack of control over the work environment (Marmot et al. 1997). Bartley's (2004) typology of causal pathways between socio-economic standing and health provides insight into the complex nature of this relationship. It assigns causal import to, variously, materialist, cultural/behavioural, psychosocial, life course and political economy domains, interpreting the social determination of health as a shifting sum of these parts. Raphael (2010b) applies this matrix to child health and development, yielding a powerful explanatory model for the entwined realities of childhood poverty, disease and underdevelopment. The materialist locus identifies parental income and employment status as primary determinants of children's access to all other determinants, including nutrition, housing and education. The cultural/behavioral sphere suggests that parental beliefs, values and norms play an essential role in determining children's exposures to noxious or salutary influences. Children's perceived status in society, levels of psychosocial stress, sense of control and family and social environments are seen as psychosocial determinants of health. Events starting before birth, perhaps even before conception, and continuing into early childhood are captured in the life course domain. Finally, the political economy sphere reinforces the evidence that political processes and societal distribution of power affect everything distally, including the spread of economic and other resources (Raphael 2010b). Despite the raft of evidence linking social circumstance to health outcomes, scientific explication of these links has lagged. The biological mechanisms through which environmental factors condition and reinforce lasting changes in health states throughout the life course have proved largely elusive. However, recent discoveries in neurodevelopment are beginning to shed light on the causal pathways that underlie the life course theory of outcome determination. Predictably, the emerging story is as rich and complex as nature itself, and reinforces the need for a nuanced appraisal of the flow of traffic between our health and our social environment.

\section{Early Childhood Development Experience-Based Brain Development}

The field of epigenetics - the study of heritable changes in gene function that occur without alterations to the deoxyribonucleic acid (DNA) sequence - has exposed the dynamic interplay 
between biology and society, challenging dichotic conceptions of nature versus nurture. Recent elegant and thought-provoking evidence suggests that the social environment has a profound impact upon the function of one's genes, providing the context and stimulus for the variable expression of an inherited code. Brain development is the quintessential case in point. Early experience appears to exert a critical and lasting influence on neuronal development, suggesting the potential for marked neural plasticity. Data from various animal studies demonstrate that perceptual inputs spur the elaboration of new axonal projections, orchestrate synaptic pruning and foster synapse consolidation (DeBello et al. 2001; Wallhausser-Franke et al. 1995). Certain periods of neurodevelopment have proven particularly sensitive to adaptation; a few of these temporal windows permit permanent changes to the developing brain (Knudsen 2004). The role of early experience in conditioning these changes is considerable.

\section{The political system - with its very short election-re-election cycle and fragmented accountability processes - often seems incapable of making the "big" decisions.}

Fish et al. (2004) provide support for this concept, and its epigenetic basis, in studies of nurturing among rats. Maternal neglect induces higher levels of DNA methylation in the infant hippocampus, impairing negative feedback to the pups' hypothalamic-pituitary-adrenal (HPA) axis. This "sensitiveperiod" change drives sustained increases in stress reactivity, which in turn heightens the risk of cardiovascular, endocrine and neuropsychiatric pathology. Caspi et al. (2003) have uncovered similar epigenetic processes at work in mental health. Their work demonstrates that the interaction between genes and the social environment in childhood determines subsequent resiliency to mental illness. The affective damage wrought by childhood abuse among children in the Dunedin birth cohort was heavily determined by allelic variance within their serotonin transporter gene. Those homozygous for the long gene structure, the protective genotype, were resilient in the face of abuse and had low rates of depression as adults. Those homozygous for the short gene structure, by contrast, proved highly susceptible to depression secondary to abuse during childhood. Heterozygotes displayed an intermediate phenotype. However, a genotype predictive of increased susceptibility to depression in adulthood was found to depend on social circumstance for its expression. Even children with the short gene structure were spared higher rates of depression provided they were raised in a supportive environment (Caspi et al. 2003).

\section{Social Determinants of ECD}

The crucial impact of sensitive-period experience is evident in studies of ECD at the population level. In a landmark study, Hart and Risley (1995) tracked language development among children in different strata of American society, demonstrating a cumulative gap of 30 million heard words between children of professional parents and children in families on welfare by age four. The impact of this early experience endured: language skill at age 10 correlated closely with vocabulary observed at age three. In Canada, developmental mapping of children in all school districts in British Columbia revealed disparate outcomes between children of different social strata by age four (Human Early Learning Partnership 2005).

Interventions to attenuate developmental risks in vulnerable groups of children have consistently catalogued developmental gains. Sustained linguistic, cognitive and behavioural benefits to early childhood education and care (ECEC) interventions have been observed in settings as diverse as Jamaica, Cuba, Romania and the United States (Commission on Social Determinants of Health 2008). For instance, an observational study of Romanian adoptees into Canadian homes found significant cognitive and behavioural differences between children adopted in the first four months in life versus those adopted after eight months of age. Those adopted later scored lower on cognitive testing and suffered from higher rates of attention deficit and other behavioural disorders (Ames 1997). Grantham-McGregor et al. (1991) examined the effects of nutrition and stimulation on stunted children in Jamaica. Their study yielded proof of significant improvements in development with either nutrition or stimulation alone, and even larger cumulative developmental strides among children who received both interventions; in fact, the latter group closed the developmental gap between themselves and healthy peers in a mere 24 months. The seminal Abecedarian study evaluated the impact of supplementary ECD programming for at-risk African American children in North Carolina. It randomized children to the normal school curriculum, a preschool program and a special school program, in various permutations. The children who received both supplementary preschool and school programming performed far better on measures of reading and mathematics than did their peers in the control and partial intervention arms, with persistent trends observed at 20 years (Campbell and Ramey 2002). This study demonstrates the enduring salutary effects of ECD programming on subsequent development, and lends empirical weight to Knudsen's notion of sensitive-period development as the preschool intervention conditioned future gains in the school program. These and other studies provide compelling evidence for the social determination of ECD, through varied but intermingled factors such as income, social cohesion, education, nutrition and early nurturing.

Evolving knowledge of neural epigenetics and the impact 
of early experience has profound implications for our understanding of child health and development. The manner in which social milieux mould development over the life course is only now coming to light, but the awareness that biology is implicated and adapted in this process is transformative. If sensitive-period experience shapes developmental opportunities throughout the lifespan, it has the capacity to engender durable and heritable patterns of social deprivation and illness. This challenge to genetic teleology provokes a reappraisal of normative presumptions about health inequalities. The lasting effects of early experience radically condition equality of opportunity, both into adulthood and across generations. Knowledge of this fact has arguably redoubled the importance of mitigating disparities in social circumstance as a means to attenuate enduring patterns of health inequality.

\section{From Science to Policy}

The recent WHO Commission on the Social Determinants of Health has sought to shift the weight of the accrued evidence on a social gradient in health, and its implied normative challenge, into a foundation for 21 st century global social policy. Its call to arms - an aspiration to "close the health gap in a generation" - seeks to redouble political focus on the social determinants of health as a means of realizing broad gains in health equity (Commission on Social Determinants of Health 2008). The commission explored a broad range of systems and policies that bear on the social determination of health, resulting in the development of three overarching goals: improve daily living conditions for all, mitigate inequities in the distribution of power and implement systems for ongoing evaluation and management of action taken. The report stipulates reform on a range of policy fronts, including ECD, the natural environment, employment, social protection and health systems, among others (Commission on Social Determinants of Health 2008). The commission's report provides fertile ground for policies promoting health equity to take hold. More fundamentally, it has thrust the notion of social determination of health, and the role of ECD therein, out of academia and onto the world stage.

What do these goals mean in the Canadian context? Despite its place among the world's wealthiest countries, with enormous natural resources and a relatively small population, Canada's track record in key outcomes such as rates of child poverty, infant mortality and low birth weight is anything but enviable. We trail behind a considerable number of countries that have parlayed evolving knowledge on ECD into actions and outcomes. Our relative childhood poverty rate is among the worst of all Organisation for Economic Cooperation and Development (OECD) countries, and yet we spend the least public money on ECEC services $-0.25 \%$ of GDP, compared with $1.2-1.5 \%$ in many other countries. Less than $20 \%$ of Canadian children aged zero to three are enrolled in child care.
Cuba, by contrast, boasts almost universal enrolment in ECEC services and has achieved national literacy scores well above a number of richer countries. Canada comes dead last in a recent international league table on ECD programming, fulfilling only one of 10 key benchmarks (OECD 2006).

Raphael (2010a) has documented Canada's relative ranking among the 21 wealthiest nations on six thematic sets of indicators of child well-being. Canada ranks sixth on maternal well-being, 13th on health and safety, second on educational well-being, 18th on relationships, 17th on behaviours and risks and 15th on subjective well-being. What accounts for this highly variable performance? Does it have anything to do with population size and migration, decentralization of decision-making or a slavish commitment to market economies? Canada's largest cities have become the stage for impressive demographic shifts, making cities such as Toronto among the most diverse in the world. But it is often these immigrants and refugees who are most disadvantaged, falling easy prey to social conditions that abet higher rates of chronic disease. Compounding this insult, the political system - with its very short election-re-election cycle and fragmented accountability processes - often seems incapable of making the "big" decisions.

Steady progress up the ladder will require concerted effort. Any hope for Canadian policies to yield performance in the top rungs across all indicators demands acknowledgement that our much-vaunted "social safety net" has suffered steady erosion in relation to those countries that top the list. Furthermore, Canada will need to develop innovative approaches to resolving its socioeconomic and health discrepancies, given our unique challenges. The rural-urban divide is principal among them. Canada describes a small population flung across a vast land mass and bears a concomitant imbalance in the reach of its social services. Nowhere is this more obvious than among the Aboriginal communities in the north. A second major challenge is to ensure that our richly diverse population of immigrants is afforded a real opportunity to integrate into all aspects of Canadian society - not only in policy but also in fact. Our healthcare system is universal but may lack sensitivity to cultural differences and issues of literacy and numeracy. Finally, we must find a way to protect policy initiatives from the vagaries of the economy, which has lurched from feast to famine and back in a way governed more by global currents than by our own policies and programs.

The solutions seem obvious: (1) an open society that welcomes our rich diversity; (2) available, affordable education through early childhood education and beyond; (3) access to maternal healthcare that targets those most at risk and does everything to engage them; (4) the development of a more robust public health system that goes beyond routine vaccination and rudimentary nutrition; and, not least, (5) the bare bones - clean water, appropriate nutrition, affordable housing, a safe environment and opportunity for meaningful 
employment. Assessment and accountability must be an integral part of all new programs. While the costs of these solutions are considerable, the long-term returns will surely dwarf them. We cannot afford the alternative. It's Canada's time to move back to the front of the line. HQ

\section{References}

Acheson, D., D. Barker, J. Chambers, H. Graham and M. Marmot. 1998. Independent Inquiry into Inequalities in Health: Report. Norwich, United Kingdom: The Stationery Office.

Ames, E.W. 1997. The Development of Romanian Orphanage Children Adopted to Canada: Final Report. Burnaby, BC: Simon Fraser University.

Bartley, M. 2004. Health Inequality: An Introduction to Theories, Concepts, and Methods. Cambridge, United Kingdom: Polity Press.

Becker, G.S. and N. Tomes. 1976. "Child Endowments and the Quantity and Quality of Children.” Journal of Political Economy 84(4): S143-62.

Bhargava, A., D.T. Jamison, L.J. Lau and C.J.L. Murray. 2001. "Modeling the Effects of Health on Economic Growth." Journal of Health Economics 20: 423-40.

Bhargava, A. and J. Yu. 1997. "A Longitudinal Analysis of Infant and Child Mortality Rates in Developing Countries." Indian Economic Review 32: 141-51.

Black, D. 1980. Inequalities in Health: Report of a Research Working Group. London: Department of Health and Social Security.

Bloom, D.E., D. Canning and B. Graham. 2001. Health, Longevity, and Life-Cycle Savings (Commission on Macroeconomics and Health Working Group Paper No. WG1). Geneva, Switzerland: World Health Organization.

Bruntland, G.H., K. Liestol and L. Walloe. 1980. "Height, Weight, and Menarcheal Age of Oslo Schoolchildren during the Last 60 Years." Annals of Human Biology 7: 307-22.

Campbell, F.A. and C.T. Ramey. 2002. "Early Childhood Education: Young Adult Outcomes from the Abecedarian Project." Applied Developmental Science 6(1): 42-57.

Caspi, A., K. Sugden, T.E. Moffitt, A. Taylor, I.W. Craig, H. Harrington et al. 2003. "Influence of Life Stress on Depression: Moderation by a Polymorphism in the 5-HTT Gene." Science 301: 386-89.

Commission on Macroeconomics and Health. 2001. Macroeconomics and Health: Investing in Health for Economic Development. Geneva, Switzerland: World Health Organization.

Commission on Macroeconomics and Health. 2002. Health, Economic Growth and Poverty Reduction: The Report of Working Group I of the Commission on Macroeconomics and Health. Geneva, Switzerland: World Health Organization.

Commission on Social Determinants of Health. 2008. Closing the Gap in a Generation: Health Equity through Action on the Social Determinants of Health. Final Report of the Commission on Social Determinants of Health. Geneva, Switzerland: World Health Organization. Retrieved February 1, 2010. <http://www.who.int/social_determinants/final_ report/en/>.

DeBello, W.M., D.E. Feldman and E.I. Knudsen. 2001. "Adaptive Axonal Remodeling in the Midbrain Auditory Space Map." Journal of Neuroscience 21: 3161-74.

Denburg, A.E. and D. Daneman. 2010. "Pascal's Wager: From Science to Policy on Early Childhood Development." Canadian Journal of
Public Health 101(3): 235-36.

Eckstein, Z., P.T. Schultz and K.I. Wolpin. 1985. "Short-Run Fluctuations in Fertility and Mortality in Pre-industrial Sweden." European Economic Review 26: 297-317.

Fiscella, K. and H. Kitzman. 2009. "Disparities in Academic Achievement and Health: The Intersection of Child Education and Health Policy." Pediatrics 123(3): 1073-80.

Fish, E.W., D. Shakrokh, R. Bagot, C. Caldji, T. Bredy, M. Szyf et al. 2004. "Epigenetic Programming of Stress Responses through Variations in Maternal Care." Annals of the New York Academy of Science 1036: $167-80$.

Fogel, R.W. 1991. "The Conquest of High Mortality and Hunger in Europe and America: Timing and Mechanisms." In D. Landes, P. Higgonet and H. Rosovsky, eds. Favorites of Fortune: Technology, Growth and Economic Development since the Industrial Revolution. Cambridge, MA: Harvard University Press.

Fogel, R.W. 1994. Economic Growth, Population Theory, and Physiology: The Bearing of Long-Term Processes in the Making of Economic Policy (Working Paper No. 4638). Cambridge, MA: National Bureau of Economic Research.

Frank, J.W. and J.F. Mustard. 1994. "The Determinants of Health from a Historical Perspective.” Daedalus 123(4): 1-19.

Galloway, P. 1986. "Differentials in Demographic Responses to Annual Price Variations in Pre-Revolutionary France: A Comparison of Rich and Poor Areas in Rouen, 1681-1787." European Journal of Populations 2: 269-305.

Gertler, P. and J. Gruber. 2002. "Insuring Consumption against Illness." American Economic Review 92(1): 51-70.

Government of Kerala. 2006. Human Development Report 2005. Thiruvananthapuram, India: Centre for Development Studies.

Grantham-McGregor, S.M., Y.B. Cheung, S. Cueto, P. Glewwe, L. Richter, B. Strupp, and the International Child Development Steering Group. 2007. "Developmental Potential in the First Five Years for Children in Developing Countries." Lancet 369: 60-70.

Grantham-McGregor, S.M., C.A. Powell, S.P. Walker and J.H. Himes. 1991. "Nutritional Supplementation, Psychosocial Stimulation, and Mental Development of Stunted Children: The Jamaican Study." Lancet 338: 1-5.

Halstead, S.B., J.A. Walsh and K.S. Warren, eds. 1985. Good Health at Low Cost. New York: The Rockefeller Foundation.

Hart, B. and T.R. Risley. 1995. Meaningful Differences in the Everyday Experiences of Young American Children. Baltimore, MD: Brookes.

Human Early Learning Partnership. 2005. The British Columbia Atlas of Child Development. Vancouver, BC: Author. Retrieved February 10, 2010. <http://www.ecdportal.help.ubc.ca/archive/bc-atlas-childdevelopment.htm>

Jeffrey, R. 1992. Politics, Women and Well-Being: How Kerala Became a 'Model.' London: Macmillan.

Keating, D.P. and C. Hertzman. 1999. Developmental Health and the Wealth of Nations. New York: The Guilford Press.

Knudsen, E. 2004. "Sensitive Periods in the Development of the Brain and Behavior." Journal of Cognitive Neuroscience 16(8): 1412-25.

Kutty, V.R. 2000. "Historical Analysis of the Development of Health Care Facilities in Kerala State, India." Health Policy and Planning 15(1): 103-09. 
Mackenbach, J.P., I. Stirbu, A.J.R. Roskam, M.M. Schaap, G. Menvielle, M. Liensalu et al. 2008. "Socioeconomic Inequalities in Health in 22 European Countries." New England Journal of Medicine 358: $2468-81$.

Marmot, M. 2004. Status Syndrome: How Your Social Standing Directly Affects Your Health and Life Expectancy. London: Bloomsbury.

Marmot, M. 2005. "Social Determinants of Health Inequalities." Lancet 365: 1099-104.

Marmot, M., G. Rose, M. Shipley and P. Hamilton. 1978. "Employment Grade and Coronary Heart Disease in British Civil Servants." Journal of Epidemiology and Community Health 32: 244-49.

Marmot, M., H. Bosma, H. Hemingway, E. Brunner and S. Stansfeld. 1997. "Contribution of Job Control to Social Gradient in Coronary Heart Disease Incidence." Lancet 350: 235-40.

Marmot, M., M. Shipley and G. Rose. 1984. "Inequalities in Death: Specific Explanations of a General Pattern?” Lancet 1: 1003-06.

McDonald, S. and J. Roberts. 2006. "AIDS and Economic Growth: A Human Capital Approach.” Journal of Development Economics 80(1): $228-50$.

McKeown, T. 1976. The Modern Rise of Population. New York: Academic Press.

McKeown, T. and R.G. Brown. 1955. "Medical Evidence Related to English Population Changes in the Eighteenth Century." Population Studies 9: 119-41.

Miguel, E. and M. Kremer. 2004. "Worms: Identifying Impacts on Education and Health in the Presence of Treatment Externalities." Econometrica 72(1): 159-217.

Mustard, J.F. 2007. “Experience-Based Brain Development: Scientific Underpinnings of the Importance of Early Child Development in a Global World.” In M.E. Young and L.M. Richardson, eds., Early Child Development: From Measurement to Action. Washington, DC: The World Bank.

Ohlsson, A. and P. Shah. 2008. Determinants and Prevention of Low Birth Weight: A Synopsis of the Evidence. Edmonton, AB: Institute of Health Economics. Retrieved January 19, 2010. <http://www.ihe.ca/ publications/library/2009/determinants-and-prevention-of-low/>.

Organisation for Economic Co-operation and Development. 2006. Starting Strong II: Early Childhood Education and Care. Paris: OECD Publishing.

Philipson, T. and R. Soares. 2001. Human Capital, Longevity, and Economic Growth: A Quantitative Assessment of Full Income Measures (Working Paper). Washington, DC: World Bank.

Pollitt, E. 1997. "Iron Deficiency and Educational Deficiency." Nutritional Reviews 55(4): 133-40.

Raphael, D. 2010a. "The Health of Canada's Children. Part I: Canadian Children's Health in Comparative Perspective.” Paediatrics and Child Health 15(1): 23-29.

Raphael, D. 2010b. "The Health of Canada's Children. Part II: Health Mechanisms and Pathways." Paediatrics and Child Health 15(2): 71-76.

Ruger, J. 2006. "Toward a Theory of a Right to Health: Capability and Incompletely Theorized Agreements." Yale Journal of Law and the Humanities 18: 273-326.

Sachs, J. and P. Malaney. 2002. "The Economic and Social Burden of Malaria." Nature 415: 680-85.

Sen, A. 1999. Development as Freedom. Oxford, United Kingdom: Oxford University Press.
Siegrist, J. 1996. "Adverse Health Effects of High Effort-Low Reward Conditions at Work." Journal of Occupational Health Psychology 1: $27-43$.

Siegrist, J., D. Starke, T. Chandola, I. Godin, M. Marmot, I. Niedhammer et al. 2004. "The Measurement of Effort-Reward Imbalance at Work: European Comparisons." Social Science and Medicine 58(8): 1483-99.

Szreter, S. 2002. "Rethinking McKeown: the Relationship between Public Health and Social Change." American Journal of Public Health 92(5): 722-25.

United Nations Children's Fund. 2008. The State of the World's Children 2008. New York: Author. Retrieved August 10, 2008. <http://www.unicef.org/publications/files/The_State_of_the_Worlds_ Children_2008.pdf>.

United Nations Development Progamme. 2000. United Nations Millennium Development Goals. New York: Author. Retrieved March 10, 2010. <http://www.undp.org/mdg/basics.shtml>.

United Nations Development Progamme. 2003. Human Development Report. New York: Oxford University Press.

Waaler, H.T. 1984. "Height, Weight and Mortality: The Norwegian Experience." Acta Medica Scandinavica 679(Suppl.): 1-51.

Wallhausser-Franke, E., B.E. Nixdorf-Bergweiler and T.J. DeVoogd. 1995. "Song Isolation Is Associated with Maintaining High Spine Frequencies on Zebra Finch IMAN Neurons." Neurobiology of Learning and Memory 64: 25-35.

Wagstaff, A., F. Bustreo, J. Bryce and M. Claeson; World Health Organization - World Bank Child Health and Poverty Working Group. 2004. "Child Health: Reaching the Poor." American Journal of Public Health 94: 726-36.

Wilkinson, R. 1996. Unhealthy Societies: The Afflictions of Inequality. London: Routledge.

Wilkinson, R. and K. Pickett. 2009. The Spirit Level: Why More Equal Societies Almost Always Do Better. London: Allen Lane.

Wilkinson, R. and M. Marmot. 2003. The Solid Facts. Copenhagen, Denmark: World Health Organization.

Wohl, A.S. 1983. Endangered Lives: Public Health in Victorian Britain. London: J. M. Dent.

World Health Organization. 2002. The World Health Report 2002: Reducing Risks, Promoting Health Life. Geneva, Switzerland: Author.

World Health Organization. 2006. World Health Report 2006 Statistical Annex. Geneva, Switzerland: Author.

Wrigley, E.A. and R.S. Schofield. 1981. The Population History of England, 1541-1871: A Reconstruction. Cambridge, MA: Harvard University Press.

\section{About the Authors}

Avram Denburg, MD, MSc, FRCPC, is a member of the Department of Pediatrics at The Hospital for Sick Children and University ofToronto, in Toronto, Ontario.

Denis Daneman, MBBCh, FRCPC, is chair of the Department of Paediatrics, University of Toronto and paediatrician-inchief, The Hospital for Sick Children. 